\title{
Maternal Under-Nutrition: A Concept Paper
}

\author{
T. Manditsvara, Clara Haruzivishe*, E. Muzokura, J. Munsaka, A. Ndaimani \\ College of Health Sciences, University of Zimbabwe, Harare, Zimbabwe \\ Email: *claraopha@gmail.com
}

How to cite this paper: Manditsvara, T., Haruzivishe, C., Muzokura, E., Munsaka, J. and Ndaimani, A. (2020) Maternal UnderNutrition: A Concept Paper. Open Access Library Journal, 7: e6183.

https://doi.org/10.4236/oalib.1106183

Received: February 24, 2020

Accepted: November 24, 2020

Published: November 27, 2020

Copyright $\odot 2020$ by author(s) and Open Access Library Inc.

This work is licensed under the Creative Commons Attribution International License (CC BY 4.0).

http://creativecommons.org/licenses/by/4.0/

\begin{abstract}
There has been growing concern over maternal under-nutrition and its effects on pregnancy outcome. The term maternal under-nutrition is complex and rather ambiguous and fails to reflect a clear definition. Defining maternal under-nutrition will help improve diagnosis, monitoring and evaluation of the impact of under-nourishment in women to prevent associated birth outcomes. There is a direct link between maternal under-nutrition and undesired birth outcomes such as intrauterine growth restriction, pre-term labour and prematurity. This is likely to give rise to long lasting effects. Methodology Walker and Avant's strategic eight-step method of concept analysis was used in analyzing the concept of maternal under-nutrition. Walker and Avant stress the importance of antecedents and attributes in describing a concept of interest. Literature search was done in one month using Google Scholar, Pub Med and Medline as search engines. Results There are several definitions of maternal under-nutrition available online which lacks standardization. The definition for maternal malnutrition was multi-varied in some instances, it was based on clinical evaluation yet in others it was based on BMI calculations and Mid Upper Arm Circumference. Conclusion Malnutrition is both seen in over-nutrition and under-nutrition. For the purpose of this paper we look at malnutrition as it relates to under-nutrition as it is of concern to less developed countries in particular southern Africa. Maternal under-nutrition is perceived to indirectly result in increased mortality and morbidities during the perinatal period. Maternal under-nourishment should be evaluated using BMI, Mid Upper Arm Circumference, skin fold and unintended weight loss for consecutive encounters using a standard scale.
\end{abstract}

\section{Subject Areas}

Gynecology \& Obstetrics

\section{Keywords}

Concept Analysis, Definition, Maternal, Pregnancy, Under-Nutrition, Walker and Avant 


\section{Introduction}

\subsection{Maternal Under-Nutrition Globally}

Maternal under-nutrition and its effects have been under the spotlight over the years with efforts towards its reduction. However, the condition has continued to affect women of reproductive age (WRA) despite the attention it is receiving. Analysis by Black et al. 2013 [1] reviewed that universally from 1980 to 2008, underweight decreased slightly in women 20 - 49 years of age from about 15 percent to 13 percent while overweight increased from about 23 percent to 34 percent. However, underweight is 5 - 10 percentage points higher in poor countries. For example, in 5 countries (Bangladesh, Cambodia, Ethiopia, Nepal, and Senegal), 20 - 25 percent of women are underweight: an estimated 12 million pregnant and lactating women are malnourished due to protein energy deficiency. Global standing committee on nutrition highlights that many women and young children often have to walk as far as $15 \mathrm{~km}$ in search of water and food and in Zimbabwe (34\%) of all households had only one or less meals the previous day.

Maternal infections for example malaria and HIV/AIDS add majorly towards maternal under-nutrition and adverse pregnancy outcomes. According to the global burden of diseases 2010, child and maternal under-nutrition risk factors including maternal micronutrient deficiencies, suboptimal breastfeeding and childhood underweight are collectively accountable for almost $7 \%$ of the global disease burden contributing to at least a fifth of maternal deaths along with the increased probability of poor pregnancy outcomes. These are most prevalent in the regions of South East Asia, South America and Africa, with some countries in Eastern and Southern Africa Region (ESAR) having maternal under-nutrition frequency rate as high as $35 \%$. Despite the fact that there is a decline over the past few decades, the incidence of low BMI $\left(<18.5 \mathrm{~kg} / \mathrm{m}^{2}\right)$ among women of reproductive age (WRA) in Africa and Asia still a problem higher than 10\%. (Ibid) the eastern, northern and western African regions have shown some improvements; however, in southern Africa the situation has not improved or might have even worsened. Simultaneously, prevalence of overweight $\left(B M I \geq 25 \mathrm{~kg} / \mathrm{m}^{2}\right)$ and obesity (BMI $\geq 30 \mathrm{~kg} / \mathrm{m}^{2}$ ) among WRA has been rising in all regions of the world and reached more than $30 \%$ and $10 \%$ globally and in Africa respectively.

\subsection{Scope of the Problem}

Lancet 2013 highlights that there is significant contribution of under-nutrition to children, stemming from fetal growth restriction, stunting, wasting, micronutrient deficiencies, with a direct link to maternal causes. Globally, approximately 13 percent of women were estimated to be undernourished, and 38 percent of all pregnant women suffered from anemia [1] [2]. A lot of attention has been put in the assessment of malnutrition in children up to 5 years and little was done to pregnant women even though maternity under-nutrition has a direct bearing on the outcome of pregnancy. Despite the evidence of a strong association, global 
MUAC cutoffs have not been established to identify pregnant women who are undernourished and therefore at risk of adverse birth outcomes [3]. The use of BMI has also been castigated in measuring maternal malnutrition due to physiologic nature of pregnancy. Fakier, et al. [4] assert that the body mass index $\left(\mathrm{BMI}, \mathrm{kg} / \mathrm{m}^{2}\right)$ is currently the gold standard for measuring body fatness. However, pregnancy-associated weight gain and oedema, as well as late booking in our population setting, cause concern about the reliability of using the BMI to assess body fat or nutritional status in pregnancy. It is problematic that nutritional deficiencies in particular protein, vitamin A, zinc, folate, folic and iodine are not being documented properly to present a true picture in assessing the condition of the mother pre-pregnancy during and post-delivery so as to prevent devastating consequences leading to mortality and morbidities.

\subsection{Justification of the Study}

Malnutrition stunts the growth of vital organs such as bone development, the brain and the nervous system this compromises health of an individual. With concept analysis the researcher aimed at bringing to the fore understanding and awareness of nutritional assessment to policy makers and the generality of practicing midwives the role of malnutrition in child birth and the associated complications so that greater attention is paid in addressing existing disparities. Previous studies among pregnant women have shown a consistent association between low maternal MUAC and an increased risk of having an LBW baby. Despite the evidence of a strong association, global MUAC cutoffs have not been established to identify pregnant women who are undernourished and therefore at risk of adverse birth outcomes [3]. Institution of standardized MUAC cutoffs points for pregnant women could help to strengthen and complement programming in maternal health and nutrition programs. Recommendations by Khan et al., 2017 [5] are that countries and programs conduct a cost benefit analysis before adopting a specific MUAC cutoff as cutoff to identify under-nutrition in pregnant women is complex problem involving trade-offs.

\subsection{Purpose of Study}

In this concept paper, the goal of the researchers was to clarify the term maternal under-nutrition that is its antecedents, attributes and consequences for the purposes of bringing a lasting solution to averting maternal malnutrition through proper screening and interventions put in place for the purpose.

\subsection{Objective}

The researcher sought to clarify the concept of maternal under-nutrition in order to create and standardize nutritional assessment in pregnant mothers in order to extenuate malnutrition associated morbidities.

\section{Methodology}

Walker and Avant's [6] strategic eight step method of concept analysis was used 
in analyzing the concept of maternal malnutrition. Walker and Avant stress the importance of antecedents and attributes in describing a concept of interest. Literature search was done in one month using Google Scholar, Pub Med and Medline as search engines (Table 1).

\section{Maternal Under-Nutrition Definition}

Nutrition plays a role during pregnancy both to the mother and the baby's health and must be assessed continuously from pre-pregnancy and beyond child birth. The term under-nutrition does not reflect a water tight definition it is conferred with a spectrum of meanings by different individuals and institutions. Sinha et al. 2018 [13] assert that under-nutrition is a condition of imbalanced or inadequate nutrient intake by a person. Nana \& Zema 2018 [14] deduce that undernourishment is MUAC $<23 \mathrm{~cm}$ and normal MUAC $\geq 23 \mathrm{~cm}$ using non stretchable tape to measure the MUAC of the left arm with the assumption that all women were considered right handed. Medical dictionary [15] defines malnutrition as faulty nutrition resulting from mal-absorption, poor diet, or overeating. Their emphasis centered on the balance that must be taken in terms of the nutritional requirements of the body. Thesaurus dictionary expands on the nutritional requirements by stating that malnutrition is the condition that develops when the body does not get the right amount of the, vitamins, minerals, and other nutrients it needs to maintain healthy tissues and organ function.

Table 1. Literature used in the concept analysis.

\begin{tabular}{|c|c|c|c|}
\hline Author & Source & Definition & Comments \\
\hline $\begin{array}{l}\text { Halm } \\
\text { et al. } \\
1993 \text { [7] }\end{array}$ & $\begin{array}{l}\text { International Journal } \\
\text { of food microbiology }\end{array}$ & $\begin{array}{l}\text { Unintentional food } \\
\text { restriction }\end{array}$ & $\begin{array}{l}\text { They did not specify parameters } \\
\text { of food restriction }\end{array}$ \\
\hline $\begin{array}{l}\text { Schenker } \\
2003[8]\end{array}$ & Nutrition Bulletin & $\begin{array}{l}\text { Under nutrition is } \\
\mathrm{BMI}<20 \mathrm{~kg} / \mathrm{m}^{2}\end{array}$ & $\begin{array}{l}\text { The definition was given with } \\
\text { reference to BMI but attributes } \\
\text { and antecedents were not given }\end{array}$ \\
\hline $\begin{array}{l}\text { de Groot } \\
\text { et al. } \\
2017 \text { [9] }\end{array}$ & Wiley on line library & & $\begin{array}{l}\text { Gave some antecedents as price } \\
\text { hikes and poverty causing food } \\
\text { shortages }\end{array}$ \\
\hline $\begin{array}{l}\text { Moore } \\
2004[10]\end{array}$ & Journal of Nutrition & Protein energy deficiency & $\begin{array}{l}\text { Did not give the antecedents but } \\
\text { definition only }\end{array}$ \\
\hline $\begin{array}{l}\text { Veregr, } \\
\text { et al. } \\
2017[11]\end{array}$ & $\begin{array}{l}\text { Public Health } \\
\text { Nutrition }\end{array}$ & $\begin{array}{l}\text { Malnutrition is the result } \\
\text { of lack or access in the } \\
\text { provision of energy } \\
\text { and/nutrients to the body }\end{array}$ & $\begin{array}{l}\text { Undernourishment results in } \\
\text { malnutrition }\end{array}$ \\
\hline $\begin{array}{l}\text { Ahmed } \\
\text { et al. } \\
1998[12]\end{array}$ & $\begin{array}{l}\text { Journal of biosocial } \\
\text { science }\end{array}$ & $\begin{array}{l}\text { Chronic energy deficit } \\
\text { resulting in a body mass index } \\
<18.5\end{array}$ & $\begin{array}{l}\text { The definition was given in } \\
\text { terms of BMI calculation but } \\
\text { no antecedents or attributes were } \\
\text { given }\end{array}$ \\
\hline
\end{tabular}


It is any disorder resulting from an inadequate diet or from failure to absorb or assimilate dietary elements. Khan et al. [5] observe that sometimes we take nutrients, which do not provide calories according to the need of the daily activities and type a physique a person has. Malnutrition may be defined as underweight. This is in contextual meaning when referring to poverty stricken environments however; over-nutrition is also a public health concern in pregnancy and child birth and falls under the broad topic malnutrition. It is therefore important to note that malnutrition refers to lack, deficiency, excesses or imbalances in individual's intake of energy and/or nutrients. The term malnutrition covers the two contrasting groups of the condition. One is "under-nutrition" with reference to low height for age, low weight for height, underweight is low weight for age and micronutrient insufficiencies of important vitamins and minerals. It is recommended that a cost-benefit analysis be done before adopting a specific MUAC cutoff. If a cutoff with a high sensitivity is selected at the expense of specificity, health care systems must have the ability to handle large numbers of false positives women who are falsely identified as at risk [3]. The term under-nutrition literally is a term meaning "bad nutrition" and in technical terms it means lacking adequate dietary intake and manifests itself in unwanted weight loss. This paper seeks to clarify the concept of maternal under-nutrition.

\section{Antecedents}

Figure 1 shows antecedents of maternal malnutrition. Antecedents are events and circumstances which occur prior to the occurrence of the concept and often associated with the occurrence of the same concept [6]. The global economy was projected to shrink by $1.7 \%$ in 2009 . Gross domestic product (GDP) growth in developing countries was expected to slow to $2.1 \%$, and recessions were projected in Europe and Central Asia to be $(-2.0 \%)$, and Latin America and the Caribbean $(-0.6 \%)$. This global recession was coming at a time when the impact of

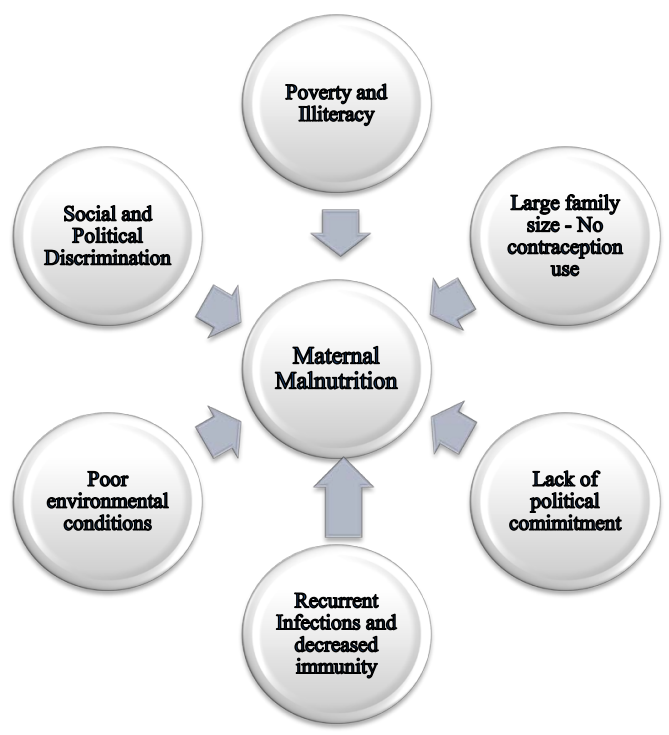

Figure 1. Antecedents of maternal malnutrition. 
the rise in food prices between 2005 and 2008 was estimated to have increased. For instance the proportion of the population of East Asia, the Middle East, and South Asia succumbing to extreme poverty rose by 1 or more percentage points. Impacts in some parts of Africa were also with variations pronounced between local and global market food prices. Overall the number of extremely poor was estimated to have increased by between 130 and 155 million globally between 2005 and 2008, with 53 million more expected in 2009. Moreover, cash inflow to developing countries would decrease as result of reductions in foreign direct investment (FDI), foreign aid and migrant workers remittance.

Global Recession: Global economy shrunk by $1.7 \%$ in 2009. Gross domestic product growth in developing countries fell by $2.1 \%$ with the accompaniment of an increase in recessions in Europe Asia and Latin America. The global recession came at a time when the impact of food prices rise increased between 2005 and 2008.

Draught and Famine: Famine in Zambia during the drought of 2001-2002, mothers who experienced high maize prices while pregnant had reduced Vitamin $\mathrm{E}$ and Vitamin A status and stunting increased among infants. Zimbabwe and Mozambique were jointly hit by the devastating effects of cyclone Idai.

Women are usually the last in receiving benefits from increased household income. They are usually the first to make sacrifices when financial situation deteriorates. This has negative repercussions because it is critically important that the woman receives adequate nutrition both for herself and growth of the child. Food shortage is a plague on pregnant women.

Biological Factors Birth spacing, age of the mother 18 - 23, infections and diarrhea, TB, measles, malaria and AIDS are all causes of maternal nutria-nutrition.

Environmental These include unsanitary living, draughts, wars, forced migration have indirect bearing on malnutrition in general.

Personal Malnutrition is caused by diet problems related to physiological loss of appetite during pregnancy, psychological problems, digestive complaints and stomach conditions. The main causes of malnutrition include changes in nutrient requirements, secondary to disease processes and drug modalities in combination with low or marginal dietary intake. Infections are common and result in anorexia, poor dietary intake, and malnutrition, which predispose the patient to another infection. Maternal malnutrition increases the risk of gestational anemia, hypertension, miscarriages and fetal deaths during pregnancy preterm delivery and maternal mortality. For new born it can cause low birth weight, fetal intrauterine growth retardation that have long lasting developmental impact in later life also quality of life and health costs. Malnutrition also affects the development of the immune system of the newborn.

\section{Attributes}

The attributes of a condition describes the common understanding of what that particular phenomena is made up of. According to Walker and Avant [6] 
attributes are those traits/characteristics of a concept that are closely linked with the concept and will assist in differentiating a particular concept from any other concept. The attributes of malnutrition are broadly divided into under-nutrition and over-nutrition; this conceptual analysis looks at attributes of under-nutrition under the following categories:

1) Body-mass index of less than $18.5 \mathrm{~kg} / \mathrm{m}^{2}$ depicts under-nutrition while $>29$ $\mathrm{kg} / \mathrm{m}^{2}$ is overweight, weight loss or weight gain is weight taken compared to the average normal

2) Weight of the individual.

3) Skinfold thickness reflects subcutaneous fat stores that are used to meet the energy needs of the fetus and the mother during pregnancy and lactation. Changes in these measurements could also be used to assess maternal nutritional status, but few studies have evaluated its variation at different gestational ages [16]. During late pregnancy, weight gain can be due to clinical edema and infant growth.

4) MUAC and skinfold measurement are substitute parameters used for nutritional assessment as they are not influenced by leg edema [17]. MUAC cut-off points of $24.5 \mathrm{~cm}$ at less than 16 weeks of gestation, $25.5 \mathrm{~cm}$ at week 28 and 26.5 $\mathrm{cm}$ at week 36 can be used as a substitute to identify both low maternal BMI and low birth-weight when maternal weight gain cannot be calculated.

5) Unplanned weight loss in the following categories;

0 no weight loss

$<5 \%$ mild

5 - 10 moderate

Above 10 severe

6) Skinfold thickness reflects subcutaneous fat stores that are used to meet the energy needs of the fetus and the mother during pregnancy and lactation. This method uses clinical evaluation of the skin quality

\section{Case Analysis}

\subsection{Model Case}

Mrs. Chatsworth walks into a clinic for booking her pregnancy at 14 weeks gestational age, with obvious signs of frailty. She had 2 previous abortions, a 5 year old boy who was born a preterm. A 24 hour dietary intake proved that she had taken only two meals the previous day with less than the necessary nutrients. She mentioned having a poor appetite and has some food preferences which she cannot afford. Mrs. Chatsworth lives in a squalid environment in Mbare. Her husband is unemployed and earns a living through "piece work/jobs" and his wage is hardly enough to buy food for the family and sometimes they get food handouts from well-wishers. Her BMI was $15.9 \mathrm{~kg} / \mathrm{m}^{2}$, MUAC $22 \mathrm{~cm}$, she has signs of anemia and HB levels were 7, $5 \mathrm{mg} / \mathrm{dl}$. She tested negative for HIV during all her previous pregnancies and also for the current one. Her weight was $52 \mathrm{~kg}$ and records indicated that she had no signifi- 
cant weight gain during the course of the pregnancy.

\section{Analysis}

The above case indicates a typical malnourished woman. All of her nutritional assessments lie below the expected values of a well-nourished mother. Her 15.9 $\mathrm{kg} / \mathrm{m}^{2}$ which falls below the minimal of $18.5 \mathrm{~kg} / \mathrm{m}^{2}$ and MUAC fell below the normal reading of $24.5 \mathrm{~cm}$.

\subsection{Contrary Case}

Mrs. Malfus booked her pregnancy at 12 weeks gestational age, she is in her mid-20s and this is her second pregnancy. She is married to an account assistant in Harare. She looks health and jovial. Nutritional assessment, she has three meals a day. She consults a dietician for her meals are able to follow given diet instructions. Her BMI was $25 \mathrm{~kg} / \mathrm{m}^{2}, M U A C 26 \mathrm{~cm}$ she weighs $62 \mathrm{kgs}$. She has a good appetite, but is very careful to avoid overfeeding. Her hemoglobin level is $12.6 \mathrm{~g} / \mathrm{dl}$. She lives with her husband and their 3 year old daughter. Her abdominal size corresponds with the gestational age.

\section{Analysis}

The above case does not lie in the category of malnutrition since none of the indicators lies anywhere closer to the abnormal ranges. She has normal nutrition and is likely to give birth to a healthy baby if she maintains her nutritional status.

\subsection{Borderline Case}

Borderline case is closely connected to the case, but has some dissimilarity that makes it inherently distinguishable from the concept being studied [6]. Mrs. Kilwinning a 29 year old mother, a civil servant who earns relatively low income. She has pica for clay soils. Nutritional assessment proves that she takes 3 meals per day with some of the nutritional requirements such as protein, carbohydrates and fats. She lives in the rural area. She is moderately pale and her HB levels are $8.5 \mathrm{mgldl}$. Her MUAC is $22 \mathrm{~cm}$. Her weight has dropped slightly from the previous month's reading by $5 \%$. She does not consult anyone for her dietary intake. Her BMI is $18.5 \mathrm{~kg} / \mathrm{m}^{2}$.

\section{Analysis}

The case lies on the boarder-line in that it has some attributes for malnutrition as some of the nutritional indicators lies on the margin. Her MUAC is 22 $\mathrm{cm}$ which is the marginal point. She also has relatively low HB levels dietary recall and nutritional uptake is normal. The low income may cause the women to afford proper nutrition

\subsection{Empirical Reference}

Empirical referents are ways in which to show or measure the existence of a concept [6] in this study the following are the required check lists: health seeking behavior, nutritional diet, family income, maternal illness, appetite, weight loss or gain, nutritional assessment tools. 


\subsection{Consequences of Malnutrition in Pregnancy}

Nutritional insults very early in pregnancy will disturb later fetal and infant growth. According to UN standing committee on nutrition risk of delivering a low birth weight baby seems to be determined in the first 10 weeks after conception and related to circulating concentrations of a placental protein in the mother. The impact of maternal anthropometry on pregnancy outcome indicated that mothers in the low quartile of pregnancy weight were associated with an increased risk of intra uterine growth retardation IUGR and LBW. The common cycle is that female infants born with Low Birth Weight (LBW) continue to experience growth failure during childhood and adolescence and are more likely to have children who are of LBW thus reducing chances of reaching an optimal weight with adequate nutrient stores before they also conceive which in turn increases likelihood of LBW infants born to such mothers. Over-nutrition women risk higher birth weight infants with a predisposition for complications such as shoulder dystocia, caesarian section, and longer periods of hospitalization.

\section{Discussion}

Maternal malnutrition is requires a clear working definition to overcome the ambiguity of malnutrition assessment in pregnant women. In general the term malnutrition refers to both under and over-nutrition. The paper attempted to give an explicit meaning of the term maternal malnutrition through an analysis of the definitions given by different authors. While maternal over-nutrition is exaggerated during pregnancy maternal under-nutrition tend to be masked by physiological changes that occur during pregnancy a situation likely to result in poor birth outcomes in both cases with over-nourished women risking difficult labor and maternal under-nutrition giving the potential for problems such as IUGR.

As a result of inconsistency of specificities among studies, it may be difficult to recommend a BMI or MUAC cutoffs for a given purpose in all settings (Tang, et al. 2016). Maternal nutritional status is determined by the use the Mid-Upper Arm (MUAC) measurements as the use of weight and the BMI are grossly affected by hormonal changes during pregnancy. The use of BMI has been criticized in measuring maternal malnutrition due to physiological changes during pregnancy (Khalid et al., 2017). However the 5 "MUST" steps for measuring malnutrition underscores that the use of MUAC points to a general indication of BMI status.

A MUAC of $<23.5 \mathrm{~cm}$ indicates that BMI is likely to be $<20 \mathrm{~kg} / \mathrm{m}$ and if MUAC is $>32.0 \mathrm{~cm}$, BMI is likely to be $>30 \mathrm{~kg} / \mathrm{m}$. Verger, Dop, and Martin-Prével, (2013) propose normal MUAC cut-off points of $24.5 \mathrm{~cm}$ at a Gestational Age (GA) of less than 16 weeks, $25.5 \mathrm{~cm}$ at $28 \mathrm{GA}$ and $26.5 \mathrm{~cm}$ at week 36 GA which can be used as a substitute to identify both low maternal BMI and low birth-weight when maternal weight gain cannot be calculated.

Maternal under-nutrition is the result from lack of or failure to access pro- 
tein-energy giving foods and other micro-nutrients as a result of unintentional restrictions to food uptake. It is evaluated clinically by the use of MUAC. If MUAC is 22.5 to 23 it is moderate under-nutrition and if it is less than $22.5 \mathrm{~cm}$ it is severe under-nutrition and obvious wasting can be marked clearly.

\section{Conclusion}

Malnutrition is both seen in over-nutrition and under-nutrition. For the purpose of this paper we look at malnutrition as it relates to under-nutrition as it is of concern to less developed countries in particular southern Africa. Maternal malnutrition is perceived to indirectly result in increased maternal and child mortality and morbidities during the perinatal period. Maternal under-nutrition should be evaluated using BMI, Mid Upper Arm Circumference, skin fold and unintended weight loss for consecutive encounters using a standard scale.

\section{Conflicts of Interest}

The authors declare no conflicts of interest regarding the publication of this paper.

\section{References}

[1] Black, R.E., et al. (2013) Maternal and Child Undernutrition and Overweight in Low-Income and Middle-Income Countries. The Lancet, 382, 427-451. https://doi.org/10.1016/S0140-6736(13)60937-X

[2] Stevens, G.A., Finucane, M.M. and Paciorek, C.J. (2016) Levels and Trends in Low Height-for-Age. In: Reproductive, Maternal, Newborn, and Child Health: Disease Control Priorities, The International Bank for Reconstruction and Development/The World Bank, Washington DC, 85. https://doi.org/10.1596/978-1-4648-0348-2 ch5

[3] Tang, A.M., et al. (2016) Determining a Global Mid-Upper Arm Circumference Cutoff to Assess Malnutrition in Pregnant Women. Food and Nutrition Technical Assistance.

[4] Fakier, A., Petro, G. and Fawcus, S. (2017) Mid-Upper Arm Circumference: A Surrogate for Body Mass Index in Pregnant Women. South African Medical Journal, 107, 606-610. https://doi.org/10.7196/SAMJ.2017.v107i7.12255

[5] Khalid, N., Aslam, Z., Kausar, F., Irshad, H. and Anwer, P. (2017) Maternal Malnutrition and Its Kick on Child Growth: An Alarming Trim for Pakistan. Journal of Food, Nutrition and Population Health, 1, 3-24. https://doi.org/10.35841/Nutrition-Human-Health.1000104

[6] Khan, A., et al. (2017) Causes, Sign and Symptoms of Malnutrition among the Children. Journal of Nutrition and Human Health, 1, 31.

[7] Walker, L. and Avant, K. (2005) Strategy for Theory Construction in Nursing. Appleton \& Lange, Norwalk.

[8] Halm, M., et al. (1993) Microbiological and Aromatic Characteristics of Fermented Maize Doughs for Kenkey Production in Ghana. International Journal of Food Microbiology, 19, 135-143. https://doi.org/10.1016/0168-1605(93)90179-K

[9] Schenker, S. (2003) Undernutrition in the UK. Nutrition Bulletin, 28, 87-120. https://doi.org/10.1046/j.1467-3010.2003.00303.x 
[10] de Groot, R., et al. (2017) Cash Transfers and Child Nutrition: Pathways and Impacts. Development Policy Review, 35, 621-643. https://doi.org/10.1111/dpr.12255

[11] Moore, V.M., et al. (2004) Dietary Composition of Pregnant Women Is Related to Size of the Baby at Birth. The Journal of Nutrition, 134, 1820-1826.

https://doi.org/10.1093/jn/134.7.1820

[12] Verger, E.O., Dop, M.-C. and Martin-Prével, Y. (2017) Not All Dietary Diversity Scores Can Legitimately Be Interpreted as Proxies of Diet Quality. Public Health Nutrition, 20, 2067-2068. https://doi.org/10.1017/S1368980016003402

[13] Ahmed, S.M., et al. (1998) Chronic Energy Deficiency in Women from Rural Bangladesh: Some Socioeconomic Determinants. Journal of Biosocial Science, 30, 349-358. https://doi.org/10.1017/S0021932098003496

[14] Sinha, S., Patro, N. and Patro, I.K. (2018) Maternal Protein Malnutrition: Current and Future Perspectives of Spirulina Supplementation in Neuroprotection. Frontiers in Neuroscience, 12, 966. https://doi.org/10.3389/fnins.2018.00966

[15] Nana, A. and Zema, T. (2018) Dietary Practices and Associated Factors during Pregnancy in Northwestern Ethiopia. BMC Pregnancy and Childbirth, 18, 183. https://doi.org/10.1186/s12884-018-1822-1

[16] Plus, M. (2012) Medical Dictionary.

[17] Araujo, C., et al. (2009) Effect of Birth Size and Proportionality on BMI and Skinfold Thickness in Early Adolescence: Prospective Birth Cohort Study. European Journal of Clinical Nutrition, 63, 634-639. https://doi.org/10.1038/ejen.2008.20 